\title{
Fitoterapia básica y podológica
}

\author{
Basic Phytotherapy and Podiatry
}

\author{
Patricia Palomo López ${ }^{1}$, Enrique Revuelta García ${ }^{2}$ \\ ${ }^{1}$ Podólogo \\ patibiom@unex.es \\ ${ }^{2}$ Podólogo. Centro Azahar División Podológica. \\ Botica1983@msn.com
}

Correspondencia:

Patricia Palomo López.

Centro Universitario de Plasencia.

Avda. Virgen del Puerto

E-10600 Plasencia

Fecha de recepción: 10 noviembre de 2010

Fecha de aceptación: 22 de febrero de 2011

Los autores declaran no tener ningún tipo de interés económico o comercial.

\section{RESUMEN}

Este trabajo pretende ofrecer una serie de conocimientos o premisas básicas sobre la Fitoterapia y como su uso nos puede ser de ayuda en Podología. Presentamos una serie de conclusiones sobre las plantas medicinales y su farmacología, así como los principios activos más importantes, los grupos en que se divide...etc. No Obstante, hablamos de las realidades fundamentales de la fitoterapia sin despreciar la Medicina Tradicional, y por supuesto, también hablamos de los inconvenientes que tiene. Intentamos aplicar la Fitoterapia a la Podología mostrando aquí una pequeña, mínima, serie de plantas medicinales que nos pueden ser de utilidad, una forma de pequeño compendio que nos muestra sus propiedades. Luego aplicamos éstos conocimientos a determinadas patologías muy frecuentes en el pie como la gota, esguinces, verrugas...etc. Y para finalizar, algunos remedios caseros y las conclusiones.

Palabras clave: Fitoterapia; plantas medicinales; Podología.

\section{ABSTRACT}

This work tries to offer a series of knowledge or basic premises on the fitotherapy and as its use can help us in chiropody. We present a series of conclusions on the medicinal plants and their pharmacology, as well as the most important active elements, the groups in that is divided...Despite, we speak of the fundamental realities of the fitotherapy without despising the traditional medicine, and by all means, also we speak of the disadvantages that it has. We try to apply the fitotherapy to the chiropody, showing here a small, minimum series of medicinal plants that can come in useful, a form of small compendium that shows its properties to us. Then, we applied these knowledges to certain very frequent pathologies in the foot, as the disease in the smaller bones of the ffetgout-, the sprains-wrench or twist the ligaments of an ankle violently, warts- small bening qrowth on the skin. And to finalize, some domestic remedies and the conclusions.

Keywords: Fitotherapy; Medicinal Plants; Chiropody.

Sumario: 1. Introducción. 2. Fitoterapia Aplicada a la Podología. 3. Patología. Tratamientos específicos a base de plantas medicinales. 4. Conclusiones. Bibliografía.

Referencia bibliográfica: Palomo López, P., Revuelta García, E.. Fitoterapia básica y podológica. Rev. Int. Cienc. Podol. 2012; 6(1): 39-50. 


\section{INTRODUCCION}

La Fitoterapia consiste en el empleo de plantas medicinales para fines terapéuticos.

Según la OMS son: "todo aquel vegetal que contiene uno o varios principios activos que pueden ser utilizados en el tratamiento curativo o paliativo de determinadas enfermedades"

Se basa en:

- Que su capacidad terapéutica depende de los principios activos.

- Se distribuyen en todas las plantas.

- Hay plantas que combinan los principios activos.

- Se deben conocer las propiedades terapéuticas de cada principio activo y en que especie se hallan.

\section{Conceptos básicos ${ }^{6}$ :}

\section{Fitofármaco}

Planta medicinal, o sus derivados galénicos, que ostenta la consideración legal de medicamento. En éste grupo se encontrarán aquellos productos que tengan la consideración de medicamentos a base de plantas medicinales (con las características que la normativa contemple) así como las fórmulas magistrales de acuerdo con los mismos criterios.

\section{Producto herbario}

Elaborado con plantas medicinales cuyas propiedades beneficiosas se basan en usos tradicionales, no contrastados por los procedimientos habituales en evaluación de medicamentos y cuya forma de utilización se encuentra al alcance de las prácticas cotidianas de los usuarios.

\section{Uso de las plantas medicinales:}

\section{Útil 0 inútil}

Existen 220.000 especies de plantas fanerógamas de las cuales sólo un 3\% han sido estudiadas para su uso medicinal.

Actualmente existe un incremento del interés de la población por las terapias alternativas, lo que ha originado un aumento del estudio sobre las propiedades curativas de las plantas.

La industria farmacéutica ha aislado los principios activos de las plantas hasta un alto grado de pureza, lo que ha permitido obtener la base de productos farmacéuticos de vital importancia.

Uno de los atractivos de ésta terapia es la baja incidencia de reacciones adversas que se producen. No obstante, su uso erróneo o la administración de dosis elevadas puede ser perjudicial.

La consuelda mayor ( syimphitiun oficinale), tiene una larga historia de uso como planta medicinal. Se usa de forma tópica para cicatrizar heridas pero se ha demostrado que su administración oral de forma prolongada puede producir cirrosis, cáncer hepático e incluso la muerte debido a su alto contenido en alcaloides.

Por todo ello, llegamos a las siguientes conclusiones sobre las plantas medicinales:

- No se deben considerar inofensivas porque tengan un largo historial en medicina popular.

- Siempre es valioso el análisis químico de las plantas medicinales populares.

- Aún en el caso de que la planta tenga toxinas, la toma ocasional de preparados diluidos podría no causar daño alguno.

- Es importante avisar a los consumidores acerca de los verdaderos riesgos de los productos elaborados con plantas.

\section{Farmacología en Fitoterapia ${ }^{1,2}$ :}

Los principios activos de las plantas medicinales son sustancias que la planta ha sintetizado y almacenado en el curso de su crecimiento con ayuda del metabolismo.

Existen diferentes tipos de principios activos en una planta, pero uno de ellos es el que determina las aplicaciones de la especie.

Los principios activos más importantes son:

- Alcaloides: se encuentran en todas las plantas como principal componente. Son venenos medicinales. Los más importantes son la atropina (toxina belladona), morfina (adormidera) y colchicina (calquito).

- Principios amargos: su base de acción se debe a la presencia de componentes amargos denominados amara. Tienen como función principal la activación de jugos gástricos y desarrollan la acción teórica general. Se usan en pérdidas de apetito o para mejorar la digestión. Eficaces en estados de 
debilidad, convalecencia, agotamiento y anemia.

Las especies típicas son: centaura menor, genciana y alcachofera.

Se dividen en tres grupos:

- Amara tónica: amargas puras.

- Amara aromática: mezcladas con aceites esenciales (sabor amargo-aromático). Las principales son el ajenjo, artemisa, angélica, cardo santo...Actúan sobre el estómago y funcionan como antisépticos, antibacterianos, antiparasitarios y diuréticos.

- Amara ácrica: contienen sustancias picantes (sabor amargo-picante). Son especies exóticas como jengibre y pimienta...Tienen función circulatoria.

\section{Realidades fundamentales de la Fitoterapia ${ }^{6}$ :}

a. Es probable que las hierbas que se venden a granel no tengan ningún valor. Las plantas secadas se deterioran con la exposición al aire, la luz y la humedad. Las hojas y flores se deterioran muy rápido, mientras que las cortezas y raíces más lentamente. Cuanto más trituradas estén, más rápido pierden sus buenas cualidades. No se deben comprar hierbas secas enteras guardadas en cajas o frascos.

b. Es muy probable que las hierbas en polvo no tengan ningún valor. Una causa importante del deterioro de las plantas secas es la oxidación. Cuanto mayor es la superficie expuesta al aire, más rápido se oxida, por eso se oxidan tanto las plantas en polvo.

c. Los productos herbolarios pueden estar contaminados o adulterados. Según haya sido el método de cultivo y la manipulación de las plantas antes de procesarlas, podrían llevar pesticidas y mohos y estar mezcladas con otras plantas, ya sea por casualidad o deliberadamente. Los mejores preparados serán los que hayan sido recolectados de manera silvestre o de modo biológico.

d. Los mejores preparados son las tinturas o extractos secados al frío. Las tinturas son extractos de plantas frescas o secadas, que normalmente contienen un porcentaje elevado de alcohol de cereal para impedir el deterioro. Son muy estables y proporcionan la actividad beneficiosa.

e. Dejar de tomar el producto si hay una reacción adversa. Es posible también una reacción alérgica.

f. No tomar remedios a menos que sean necesarios, no son suplementos dietéticos.

g. Experimentar con los remedios. Cada uno funciona de forma diferente.

h. La mayoría de las plantas medicinales desarrollan plenamente su eficacia sólo cuando se las emplea en períodos de tiempo prolongados.

\section{Presentación del medicamento fitoterapéu- tico:}

Uso interno: tinturas, esencias, extractos, infusión, alcohol, polvo...

Uso externo: ungüentos, pomadas, aceites, alcohol, inhalaciones...

\section{FITOTERAPIA APLICADA A LA PODOLOGÍA}

Argumentos a favor del uso de plantas medicinales, que sin desmerecer a los medicamentos convencionales, pueden ser tenidos en cuenta a la hora de tratar determinadas situaciones que afecten a la salud:

- Reparación global del organismo.

- Mayor efecto preventivo.

- Menores efectos secundarios.

- Efecto más duradero, debido a su mejor tolerancia los tratamientos pueden seguirse durante largos periodos de tiempo.

- Acción polivalente, ya que a diferencia de los medicamentos (que son prescritos para una dolencia muy específica), las plantas tienen múltiples propiedades, por lo que pueden actuar sobre diferentes dolencias al mismo tiempo.

- Complemento seguro, pueden servir como complemento a tratamientos con medicamentos convencionales con un menor riesgo de interacciones. 


\section{Inconvenientes:}

- Posibles alergias

- Duración de los tratamientos

- Efecto lento

- Constancia en los tratamientos

\section{Por qué curan las plantas ${ }^{1}$ :}

La fuerza curativa y rehabilitadora de las plantas radica en la amplia variedad de principios activos que estas contienen, se han identificado más de 12.000 principios activos, a continuación se detallan algunos de los más frecuentes en las plantas medicinales:

- Mucílagos: Lubrican y protegen las mucosas del aparato digestivo, evitando la irritación y la acidez.

- Inulina: Glúcido formado por cadenas de fructosa, al no contener glucosa es mucho mejor tolerada por diabéticos y favorece las funciones del hígado.

- Aceites volátiles (esenciales): Tienen poderes antiinflamatorios, estimulantes, laxantes y antisépticos, con capacidad para reducir el colesterol y proteger la piel.

- Vitaminas y minerales.

- Flavonoides: Refuerzan la pared capilar y favorecen la circulación.

- Saponinas: Tienen efectos diuréticos y expectorantes.

- Taninos: Tienen un fuerte efecto astringente y antihemorrágico, favorecen la reducción de las inflamaciones y la cicatrización de las heridas.

- Ácidos orgánicos.

- Principios amargos: Estimulan la secreción de las glándulas salivares y regulan las funciones del aparato digestivo.

\section{Algunas plantas de interés en podología ${ }^{1,2}$ :}

\section{Abedul (Betula pendula Roth)}

P. Activos: Aceite esencial, flavonoides, sales potásicas, ácido botulínico, betolinol y taninos en la corteza.

Propiedades: Diurético, antiséptico, antiin- flamatorio, analgésico, astringente y cicatrizante.

Indicaciones: Su principal virtud es la activación de la orina y la depuración del organismo en general, facilita la eliminación de agentes tóxicos como la urea y el ácido úrico. Contribuye a reducir la hipertensión arterial (cuando esta es de origen renal) y tiene capacidad para reducir la inflamación y aliviar el dolor en casos de artritis, artrosis, reuma o problemas musculares.

Toxicidad: Ninguna.

Precauciones: Contraindicado cuando exista hipersensibilidad a los salicatos, las personas hipertensas con cardiopatía no deben consumirlo sin control médico. No se deben utilizar tinturas ni extractos durante el embarazo.

\section{Árbol del Té (Malaleuca alternifolia)}

Principios activos: Aceite esencial con terpinenos con gamma terpineno y cineol.

Propiedades: Antiséptico, antibacteriano, antiviral, antiinflamatorio, antifúngico, expectorante y balsámico.

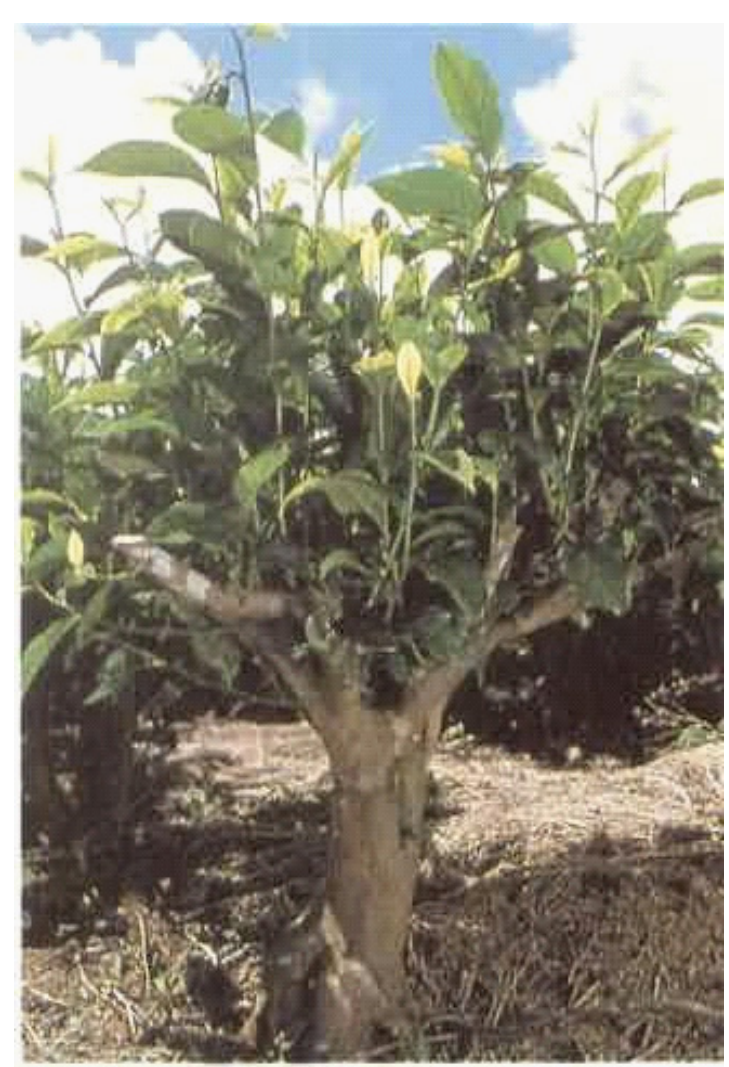


Indicaciones: Protector natural de la piel con fuerte poder antiséptico y antiinflamatorio, penetra fácilmente en la piel, estimula su regeneración y no irrita las mucosas. Está muy indicado para tratar granos, verrugas, hiperqueratosis, herpes, hongos, heridas infectadas y ayuda contra la psoriasis.

Toxicidad: Ninguna.

Precauciones: No ingerir el aceite esencial si no es bajo supervisón médica, evitar usos prolongados.

\section{Árnica (Árnica montana L.)}

Principios activos: Aceite esencial, Flavonoides, ácido cinámico y cafeico, lactosas, mucílagos y polisacáridos.

Propiedades: Analgésica, antiinflamatoria, cicatrizante, antiséptica y antifúngica.

Indicaciones: Por su elevada toxicidad su uso se reserva para aplicaciones externas, a dosis muy pequeñas se emplea vía oral en curas homeopáticas para combatir el dolor. Esta considerado el antiinflamatorio a nivel externo más potente, ya que combate el dolor muscular y disminuye todo tipo de inflamaciones. Favorece el riego sanguíneo local y acelera la cicatrización de heridas. Es igual de útil para disminuir la inflamación interna y rebajar el dolor en problemas osteoarticulares, gingivitis, faringitis, amigdalitis y dolor de muelas.

Toxicidad: Muy alta.

Precauciones: La intoxicación con árnica puede producir vértigos, mareos, alteraciones nerviosas y alucinaciones. Deber evitarse su ingestión.

\section{Bardana (Arctium lappa L.)}

Principios activos: Inulina y mucílagos en la raíz, arctiopicrina, arctiína, aceite esencial, ácidos fenólicos, fitosteroles y taninos.

Propiedades: Depurativa, diurética, desintoxicante, antibacteriana, colerética, hipoglucemiante, digestiva, astringente y cicatrizante.

Indicaciones: Planta purificadora del organismo en general, adecuada para personas que han descuidado su cuerpo, esto sumado al sedentarismo contribuye a la obesidad. Combate infecciones de las vías urinarias, facilita la eliminación de toxinas, evita la formación de cálculos en el riñón, contribuye a disminuir la tensión arterial, también actúa como regulado- ra del azúcar en sangre y como bálsamo depurativo, ideal para eliminar impurezas y defectos de la piel (acné, granos, prurito, eccemas, hongos y forúnculos.

Toxicidad: Ninguna.

Precauciones: En el tratamiento de la hipertensión se debe consultar con un especialista para tener en cuenta una posible descompensación.

\section{Caléndula (Calendula officinalis $\mathbf{L}$.)}

Principio activo: Aceite esencial, flavonoides, glucósidos amargos, resinas y mucílagos.

Propiedades: Antiinflamatoria, cicatrizante, antiséptica, antibiótica, colerética, antiparasitaria, fungicida, desintoxicante y antiespasmódica.

Indicaciones: Es una de las plantas mejor dotadas para combatir problemas dermatológicos, debido a su acción antiinflamatoria y cicatrizante es muy eficaz para tratar irritaciones de la piel, así como verrugas, hiperqueratosis, hongos y acné. Acelera la cicatrización, favorece el riego sanguíneo de la zona afecta y combate la posible infección. Eficaz contra quemaduras solares leves. Como uso tópico se recomienda para tratar encías inflamadas e inflamaciones vaginales. Ayuda a regular el ciclo menstrual y contribuye a suavizar los dolores menstruales, también evita flujos excesivos o irregulares.

Precauciones: La planta fresca puede provocar irritación por contacto directo, debe evitarse su uso en periodos de embarazo y lactancia.

\section{Camomila o Manzanilla (Chamomilla recutita)}

Principios activos: Aceite esencial, Flavonoides, principios amargos, ácido salicílico, ácidos fenólicos y vitamina C.

Propiedades: Antiinflamatoria, digestiva, colerética, antiespasmódica, sedante, analgésica, antiséptica y cicatrizante.

Indicaciones: Tal vez sea la infusión más conocida, tiene usos múltiples y variados. Es un excelente tónico digestivo, reduce la hinchazón abdominal, es un bálsamo contra diarreas veraniegas y cólicos con flatulencias. Suaviza los dolores menstruales, regula el ciclo (especialmente en dismenorreas) y evita las nauseas durante el embarazo. Se utiliza para paliar cándi- 
das, cólicos e insomnio. En forma de emplastes se utiliza para rebajar la inflamación de heridas, llagas y picaduras. El aceite esencial se utiliza para reducir el dolor muscular debido a malas posturas, golpes o lesiones deportivas leves.

Toxicidad: Leve

Precauciones: No ingerir el aceite esencial durante el embarazo y la lactancia.

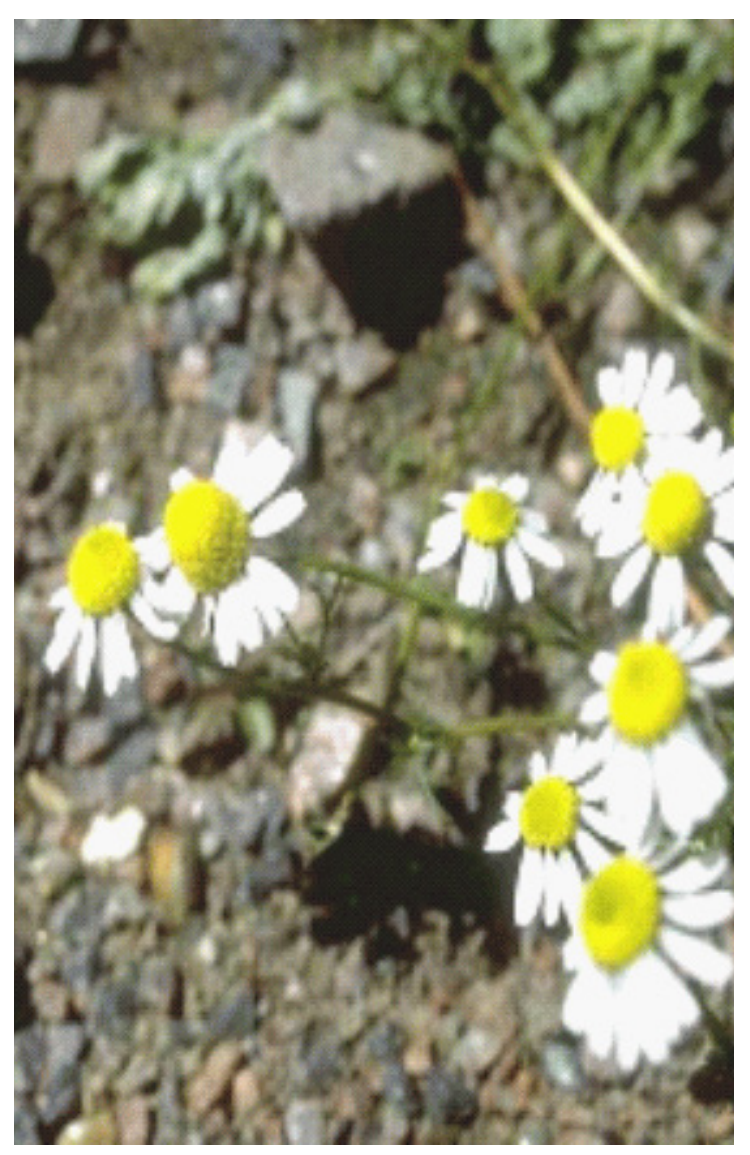

Castaño de Indias (Aesculus hippocastanum L.)

Principios activos: Saponósidos triterpénicos, flavonoides, pectina, sales minerales, vitamina $\mathrm{P}$ y taninos en las semillas. Fitosteroles y taninos en las hojas; taninos y glucósidos en la corteza.

Propiedades: Venotónico, vasoconstrictor, astringente y antiinflamatorio.

Indicaciones: La aescina sumada a la acción de la vitamina $P$ aumenta la resistencia de los capilares y tonifica las venas, lo que explica su acu- sado efecto antiinflamatorio y antiedematoso.

Toxicidad: Moderada.

Precauciones: La ingesta del fruto de este árbol puede provocar gastroenteritis, vómitos, ansiedad y somnolencia. Debe evitarse durante el embarazo y lactancia, así como en personas que sigan tratamientos con anticoagulantes. En general se aconseja no administrar castaña de indias sin vigilancia médica.

\section{Ciprés (Cupressus sempervirens L.)}

Principios activos: Aceite esencial con canfeno, alfa-pineno y cedrol, flavonoides y taninos.

Propiedades: Astringente, antidiarreico, hemostático, venotónico, analgésico, antiinflamatorio, antiséptico y antiviral.

Indicaciones: Esta recomendado para fortalecer los vasos sanguíneos, en forma de lavados y pomadas facilita la curación de varices, flebitis y hemorroides. La decocción de los gálbulos frescos del ciprés es muy útil en baños para eliminar la bromohidrosis. En uso tópico también se utiliza sobre verrugas, úlceras varicosas y para mitigar dolores reumáticos.

Toxicidad: Moderada.

Precauciones: Se recomienda no utilizarlo durante el embarazo y la lactancia, y debe evitarse ingerir el aceite esencial.

\section{Cola de caballo (Equisetum arvense $\mathbf{L}$.)}

Principios activos: Rica en sales minerales, sapónidos, ácidos equisetólido y gálico, flavonoides y taninos.

Propiedades: Diurética, remineralizante, depurativa, astringente, hemostática y cicatrizante.

Indicaciones: Su alto contenido en sílice y potasio le confieren un excepcional poder depurativo y remineralizante, es un buen diurético, indicado en infecciones renales y urinarias, oliguria, gota e hipertensión arterial. También destaca por su poder protector de la piel, estimula y repara tejidos dañados a causa del embarazo, celulitis, previniendo la aparición de estrías. Se aconseja así mismo para el tratamiento de problemas reumáticos, artríticos, consolidación de fracturas y osteoporosis.

Toxicidad: Leve

Precauciones: Se debe evitar si existe irritación de la mucosa gástrica. Se desaconseja durante el embarazo y la lactancia. 


\section{Diente de León (Taraxacum officinale We- ber)}

Principios activos: Inulina, ácidos fenólicos, taraxacósido, taraxacina, fitosteroles, mucílagos y sales minerales en la raíz. Flavonoides, cumarias, sales minerales y vitaminas B y C en las hojas.

Propiedades: Depurativo, desintoxicante, diurético, colerético, digestivo y laxante.

Indicaciones: Su principal capacidad es limpiar el organismo de agentes tóxicos. Actúa sobre vesícula y riñones impidiendo la formación de cálculos, facilitando la emisión de orina y la eliminación de toxinas. En uso externo es muy eficaz como depurativo de impurezas de la piel como el acné, granos, eccemas, urticarias, sarpullidos y quemaduras.

Toxicidad: Leve.

Precauciones: Es un planta amarga cuyo uso continuado puede causar molestias en las mucosas gástricas. El látex que exuda puede irritar la piel por contacto.

\section{Fumaria (Fumaria officinalis L.)}

Principios activos: Ácido fumárico, ácidos fenólicos, flavonoides, alcaloides, sales potásicas $\mathrm{y}$ taninos.

Propiedades: Digestiva, colerética, colagoga, diurética, depurativa, laxante, cardiotónica, antiarrítmica, antiinflamatoria, analgésica y expectorante.

Indicaciones: Planta depurativa que destaca por su acción protectora y restauradora del hígado y vesícula. Estimula y favorece la secreción de bilis, impide la formación de cálculos y repara daños causados por trastornos como la hepatitis y la ictericia. Muy activa para tratar afecciones graves de la piel como eccemas, forúnculos y psoriasis.

Toxicidad: Moderada

Precauciones: Planta potencialmente tóxica, su uso debe estar sujeto al asesoramiento de un especialista. Está contraindicada en caso de hipertensión arterial. A dosis bajas es hipertensiva y a dosis superiores puede llegar a ser hipotensora. No utilizar durante periodos prolongados.

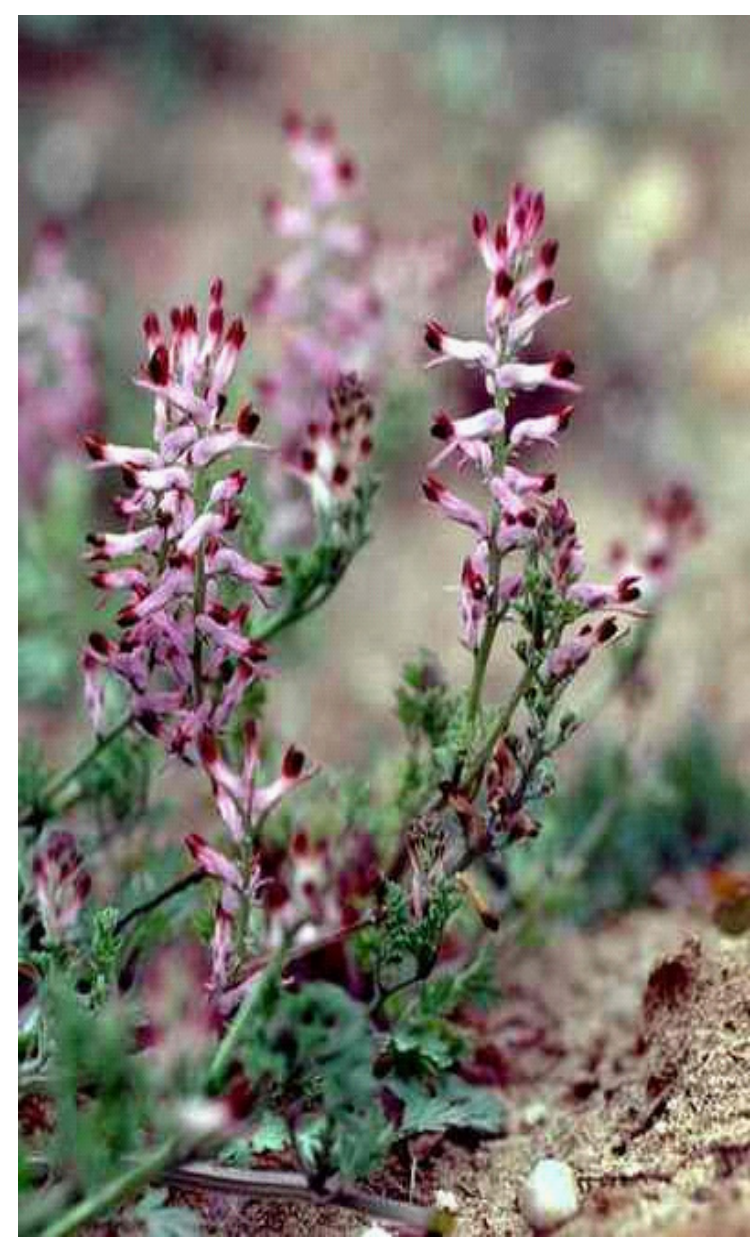

Hamamelis (Hamamelis virginaria L.)

Principios activos: Aceite esencial. Taninos, ácido gálico, principios amargos y Saponósidos.

Propiedades: Astringente, antidiarreico, hemostática, cicatrizante, antiinflamatoria y vasoprotectora.

Indicaciones: Es una de las plantas más eficaces protectoras de la piel, su uso tópico consigue reforzar las proteínas de la piel y la previene contra las agresiones externas, haciéndola más resistente a la inflamación. Se recomienda en heridas, llagas, úlceras cutáneas, eccemas, sarpullidos, granos, quemaduras solares y herpes. Es especialmente activa para aliviar hemorroides y varices, así como para tratar contusiones, torceduras, dolores articulares y venas dañadas.

Toxicidad: Leve.

Precauciones: Su alto concentración de taninos puede provocar irritaciones en la mucosa gástrica. 


\section{Harpagofito (Hargophytum porcumbers D.C.)}

Principios activos: Glucósidos amargos, harpagoquinona, glucósidos fenólicos, fitosteroles, aceite esencial y azúcares.

Propiedades: Analgésico, antiinflamatorio, antiespasmódico, febrífugo hipoglucemiante, estimulante digestivo y colagogo.

Indicaciones: El tubérculo de esta planta es uno de los analgésicos naturales más eficaces, muy útil contra los dolores reumáticos y artríticos y en general para mitigar dolencias del aparato locomotor. Se le atribuye también la capacidad de regular el nivel de colesterol en sangre, mejora la circulación y aumentar la emisión de orina.

Toxicidad: Leve.

Precauciones: Evitar su uso durante el embarazo y la lactancia, así como en caso de padecer úlcera gastroduodenal o síndrome de colon irritable.

\section{Nogal (Juglans regia L.)}

Principios activos: En las hojas, ácidos elágico y gálico, flavonoides, aceite esencial y taninos. En las semillas ácidos grasos insaturados (linoleico y alfa-linoleico), vitaminas A, B y E, sales minerales.

Propiedades: Astringente, antidiarreico, hemostático, cicatrizante, antiséptico, antiinflamatorio, vermífugo, digestivo, vitamínico, remineralizante, hipoglucemiante, emoliente y diurético.

Indicaciones: Las infusiones de hojas de nogal son un excelente remedio para atajar diarreas y en uso tópico para eliminar impurezas como granos y espinillas, para sanar llagas en la boca También so buenas para aliviar cólicos y vómitos, también favorecen la expulsión de parásitos intestinales. Tiene cierta capacidad para disminuir el contenido de glucosa en sangre por lo que se recomienda como apoyo en diabetes suaves.

Precauciones: Evitar en casos de gastritis y úlcera gastroduodenal pues el contenido en taninos puede provocar irritación de mucosas. No combinar con tratamientos con remineralizantes y utilizar bajo control médico en caso diabetes.
Ortiga verde (Urtica dioica L.)

Principios activos: Ácidos orgánicos, flavonoides, mucílagos, vitamina A, sales minerales, histamina, acetilcolina y serotonina en los pelos urticantes, ácido linoleico en las semillas, fitosteroles y taninos en las raíces.

Propiedades: Remineralizante, reconstituyente, antianémica, diurética, depurativa, hipoglucemiante, hipotensora, colagogo, astringente, antihemorrágica, cicatrizante y antiinflamatoria.

Indicaciones: Es un excelente reconstituyente natural, consumida como verdura aumenta la secreción biliar y pancreático. Disminuye el contenido de glucosa en sangre y favorece la circulación sanguínea. Se ha recomendado como ingrediente en comulaciones medicinales para tratar la diabetes la hipertensión arterial y el exceso de ácido úrico en sangre.

Toxicidad: Moderada.

Precauciones: Su uso como diurético en caso de hipertensión, cardiopatía e insuficiencia renal debe estar bajo examen previo. Se debe evitar el contacto directo con la piel por su aludido efecto urticante.

\section{Podófilo (Podophyllum peltatum L.)}

Principios activos: Podofilotoxina en la resina, peltatinas, flavonoides y gomas.

Propiedades: Laxante, purgante, colagogo, antiviral, antitumoral.

Indicaciones: La podofilotoxina incluso en dosis bajas se muestra como purgante energético por lo que su uso debe estar sujeto a precauciones. Diversas investigaciones han probado

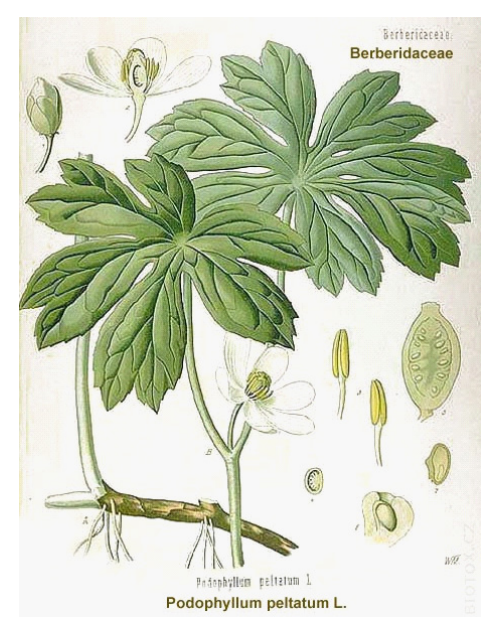

Revista Internacional de Ciencias Podológicas 2012, Vol. 6, Núm. 1, 39-50 
que esta sustancia puede ser útil en el tratamiento de ciertos tumores cancerígenos. Se le atribuye la capacidad de impedir la división celular por lo que se prescribe para erradicar verrugas (disuelve la capa córnea de las mismas), papilomas, condilomas y otras afecciones víricas de la piel.

Toxicidad: Muy alta.

Precauciones: Toda la planta, no sólo la raíz, es muy tóxica. En ningún caso se deben ingerir los frutos, ni las hojas. Sólo se recomienda utilizar esta planta para su aplicación tópica en dolencias de la piel, básicamente en verrugas. Una intoxicación puede provocar vómitos, diarreas, y en casos extremos, parada cardiorrespiratoria y la muerte. El polvo de la raíz puede provocar irritación en los ojos.

\section{Sauce blanco (Salix alba L.)}

Principios activos: Ácido salicílico, vainílico y cafeico, salicina, salicortina, vainillina, flavonoides, oxalatos y taninos.

Propiedades: Analgésico, antiinflamatorio, febrífugo, antirreumático, antiespasmódico, astringente, sedante.

Indicaciones: La corteza contiene ácido salicílico, que es considerado el precursor de la aspirina, por lo que es la alternativa natural a este medicamento, pues alivia la mayoría de los síntomas por los que se toma la aspirina con la ventaja de carecer de los efectos irritantes en el estómago. Es un buen remedio contra los dolores artríticos y reumáticos, tiene la capacidad de reducir la fiebre y calmar la sensación de miembros doloridos. Como la propia aspirina, se considera adecuado para prevenir los accidentes coronarios por su efecto anticoagulante. En el pasado también se utilizó para eliminar las verrugas y los callos de la piel.

Toxicidad: Ninguna.

Precauciones: No combinar con tratamientos con anticoagulantes o derivados de ácido acetilsalicílico. Puede provocar reacciones en personas sensibles a los salicilatos, con aparición de alergias y problemas bronco-respiratorios.

\section{Saúco (Sambucus nigra L.)}

Principios activos: Aceite esencial, ácidos cafeico y clorogénico, flavonoides y sales minerales en las flores. Ácido málico y tartárico, an- ticianósidos y vitamina $\mathrm{C}$ en las bayas, taninos en la corteza.

Propiedades: Expectorante, antialérgico, diurético, antiinflamatorio, antirreumático $\mathrm{y}$ laxante.

Indicaciones: Las flores constituyen un remedio eficaz desde la antigüedad para luchar contra resfriados y alergias. Tiene la capacidad de proteger las mucosas respiratorias aumentando la resistencia frente a infecciones. Es un arma frente a infecciones por hongos, como la candidiasis, y un freno contra la aparición de urticarias. Flores y frutos se han empleado para combatir dolores reumáticos y facilitar la expulsión de toxinas a través de la orina. Uno de los usos más extendidos del saúco es para sanar infecciones de oído y para aliviar la fatiga ocular, irritaciones de los ojos y la inflamación de los parpados.

Toxicidad: Leve.

Precauciones: Se debe evitar el consumo de frutos no suficientemente maduros, debido a su potente efecto purgante pueden ocasionar diarreas y vómitos.

\section{PATOLOGÍA. TRATAMIENTOS ES- PECÍFICOS A BASE DE PLANTAS MEDICINALES}

\section{Gota:}

Enfermedad resultante de un aumento del ácido úrico en sangre, y su depósito en las articulaciones y tejido renal. También se conoce como artritis úrica o artritismo.

Fitoterapia: Ortiga verde, Diente de León, Abedul, Harpagofito y Bardana.

\section{Esguinces:}

Torcedura o distensión violenta de una articulación, que puede llegar a romper algún ligamento o fibra muscular.

Fitoterapia: Árnica y Sauce. Magnesio y Potasio.

\section{Úlceras y Heridas:}

El tratamiento se basa en plantas de acción cicatrizante y antiséptica, principalmente. Si la herida es limpia y cerrada se procederá al lavado de la herida con infusiones o decocciones 
de las plantas que veremos a continuación, y si la herida está infectada o es una herida abierta (úlceras p. ej.) se aplicaran cataplasmas o compresas.

Fitoterapia: Camomila, Nogal, Caléndula, Sanícula y Equinacea.

Hiperqueratosis: La aplicación local de plantas medicinales ablandan las hiperqueratosis, por contener sustancias como el ácido salicílico, capaces de deshacer la dura capa córnea.

Fitoterapia: Caléndula y Sauce blanco.

Verrugas: Excrecencias cutáneas debidas al crecimiento excesivo de determinadas células de la piel, en muchos casos son de origen vírico.

Fitoterapia: Podofilo y Caléndula, Tepezcohuite, Eleuterococo, Equinacea, Uña de gato.

Papilomas y Condilomas: Son pequeñas tumoraciones benignas de la piel similares a las verrugas.

Fitoterapia: Podofilo, Tepezcohuite, Eleuterococo, Equinacea, Uña de gato.

Grietas de la piel: Son pequeñas hendiduras de la piel, generalmente dolorosas, que afectan a la epidermis y a la porción superficial de la dermis.

Fitoterapia: Aloe vera, Árnica y Caléndula.

Eccemas: Son sinónimo de dermatitis, abarcan pues todas las inflamaciones de la piel. El tratamiento de los eccemas a través de la fitoterapia requiere aplicaciones locales a base de lociones, cataplasmas, etc y tratamiento interno que consiste en plantas depurativas.

Fitoterapia: Ortiga verde, Camomila, Fumaria, Diente de León, Abedul y Aloe vera. Manganeso, Azufre, Yodo y Silicio.

Piel seca: Se utilizan plantas que protegen y estabilizan la capa grasa de la piel, con lo que se detiene el proceso de evaporación, aumentado así la hidratación y belleza del cutis.

Fitoterapia: Castaño de indias, Caléndula y Bardana.

Sudoración excesiva: Puede estar causada por infecciones agudas o crónicas, estados de debilidad y desequilibrios nerviosos, entre otras causas.

Fitoterapia: Salvia. (Uso tópico y vía oral).

Uñas frágiles: En algunos casos, la afección de las uñas puede ser síntoma de una enfermedad generalizada del organismo, por lo que se recomienda tanto el uso interno y externo de las plantas mencionadas a continuación, para contribuir al endurecimiento de las uñas.

Fitoterapia: Cola de caballo, Levadura de Cerveza y Germen de trigo. Azufre, Yodo y Silicio y Manganeso.

Micosis: Se utilizan plantas de acción antifúngica, aplicadas en forma de lociones o compresas.

Fitoterapia: Aloe vera, Propóleo, Nogal, Aceite del Árbol del Té. Selenio.

Tiña: Micosis muy contagiosa que afecta a piel y cuero cabelludo, causada por dermatofitos.

Fitoterapia: Aloe vera, Propóleo, Nogal y Aceite del Árbol del Té. Selenio.

\section{Remedios caseros:}

Fórmula con las verrugas:

- Ingredientes: Aceite esencial del árbol del té y esencia de limón.

- Preparación: Una gota de cada esencia sobre la verruga y cubrir con una gasita.

- Frecuencia: Una vez al día por la noche antes de acostarse y retirar por la mañana, continuar con el tratamiento hasta que desaparezca la verruga.

Contra hongos y pie de atleta:

- Ingredientes: 5 gotas de aceite esencial del árbol del té y una cucharadita de ungüento de caléndula.

- Frecuencia: Aplicar 3 veces al día sobre la zona afectada con una suave fricción.

Ungüento para torceduras y esguinces.

- Ingredientes: 60 grs. de árnica, vaselina o cera.

- Preparación: Fundir la cera o vaselina al baño maría y colocar la planta troceada, 
seguidamente filtramos y exprimimos la mezcla para extraer todo el líquido. Introducimos la solución en frascos de cristal, tapamos y dejamos reposar hasta que adquiera consistencia.

- Frecuencia: Aplicar el ungüento con un suave masaje sobre la zona afectada 3 veces al día.

Compresas para pieles irritadas:

- Ingredientes: A partes iguales caléndula, cola de caballo y flor de nogal (contiene yodo y taninos reforzantes para la piel).

- Preparación: Hervir durante 10 minutos una cucharada sopera rasa de la mezcla por cada $250 \mathrm{ml}$ de agua. Colocamos y empapamos unas compresas que aplicaremos sobre la zona afectada. Si se trata de una llaga es mejor aplicarla con una jeringuilla ya que se estimula y favorece el aporte de riego sanguíneo a la zona.

- Frecuencia: Repetir 3 veces al día hasta que desaparezca la irritación.

Fórmula antiinflamatoria:

- Ingredientes: 40 grs. de Harpagofito, 30 grs. de Sauce Blanco, 10 grs. de Cola de Caballo y 5 grs. de menta, por cada litro y medio de agua.

- Preparación: Hervir durante 10 minutos y dejar reposar durante otros 15 minutos.

- Frecuencia: Tomar 3 vasos al día, endulzar con miel o bien enriquecer con unas gotas de zumo de limón.

Baño contra la resaca:

- Preparación y aplicación: Poner unas gotas de aceite esencial de limón, hinojo y lavan- da en el baño, agitar para que se disuelvan e inspirar profundamente mientras dure el baño.

Decocción para los dolores musculares (Esguince, tendinitis y tirones).

- Ingredientes: 10 grs. de corteza de sauce, viburno e hipérico. Utilizar una cucharada sopera por cada $250 \mathrm{ml}$ de agua.

- Preparación: Hervir durante 5 minutos el sauce y el viburno, cuando comienza la ebullición añadir el hipérico. Dejar la mezcla 10 minutos en infusión y filtrar bien.

- Frecuencia: Tomar dos tazas al día fuera de las comidas.

\section{CONCLUSIONES}

Hoy en día la Fitoterapia, así como la mayoría de las terapias alternativas, se encuentran en auge y cada vez más población demanda tratamientos fitoterapéuticos. Es una realidad que todo éste tipo de terapias se están haciendo un hueco cada vez más evidente en la sociedad. Se hace, por tanto, necesario en las consultas de Podología un conocimiento mínimo de la fitoterapia para poder ayudar u orientar a nuestros pacientes, o conocer algunos remedios que ya traen instaurados cuando acuden a consulta. No se pretende que seamos auténticos especialistas en aplicar tratamientos a base de fitoterapia pero sí que seamos conscientes de que la Fitoterapia produce buenos resultados sin despreciar la medicina convencional y que algunas de sus aplicaciones nos pueden servir en Podología.

\section{BIBLIOGRAFÍA}

1. Cebrián J. Diccionario integral de las Plantas Medicinales.RBA Libros. $1^{a}$ Edición. Mayo 2002. Pag: $7-11 ; 15-16 ; 55-57 ; 87-88 ; 107-109 ; 144-145 ; 184-185 ; 214-216$; 261-262; 287-289; 295-297; 391-393; 427429; 445-447,524-526; 533-537.

2. Pamplona Roger, J; Enciclopedia de las plantas medicinales. Biblioteca Edición y Salud. Editorial Safeliz. $1^{\text {a }}$ Edición. Toledo. Marzo 2004.Tomo 2.Pag: 647, 657, 683-690.

3. Colegio de Farmacéuticos. Fitoterapia. Vademecum de Prescripción. Plantas Medicinales. Editorial Masson.Barcelona.1998. $3^{\text {a }}$ Edición. Pag: 11-30.

4. Cañigueral, S. Acceso a la documentación científica actual referente a las plantas medicinales.1989. Boletín A.E.F.I, $3^{a}$ Epoca(16): 21-23. 
5. Wilkinson, J.A. The Internet a Research and Information Tool for Herbal Medicine. British J. Phytotheraphy, 4: 34-45.

6. Mulet, L. Estudio Etnobotánico de la Provincia de Castellón. Castellón: Diputación Provincial,1991; Pags: 415-416. 